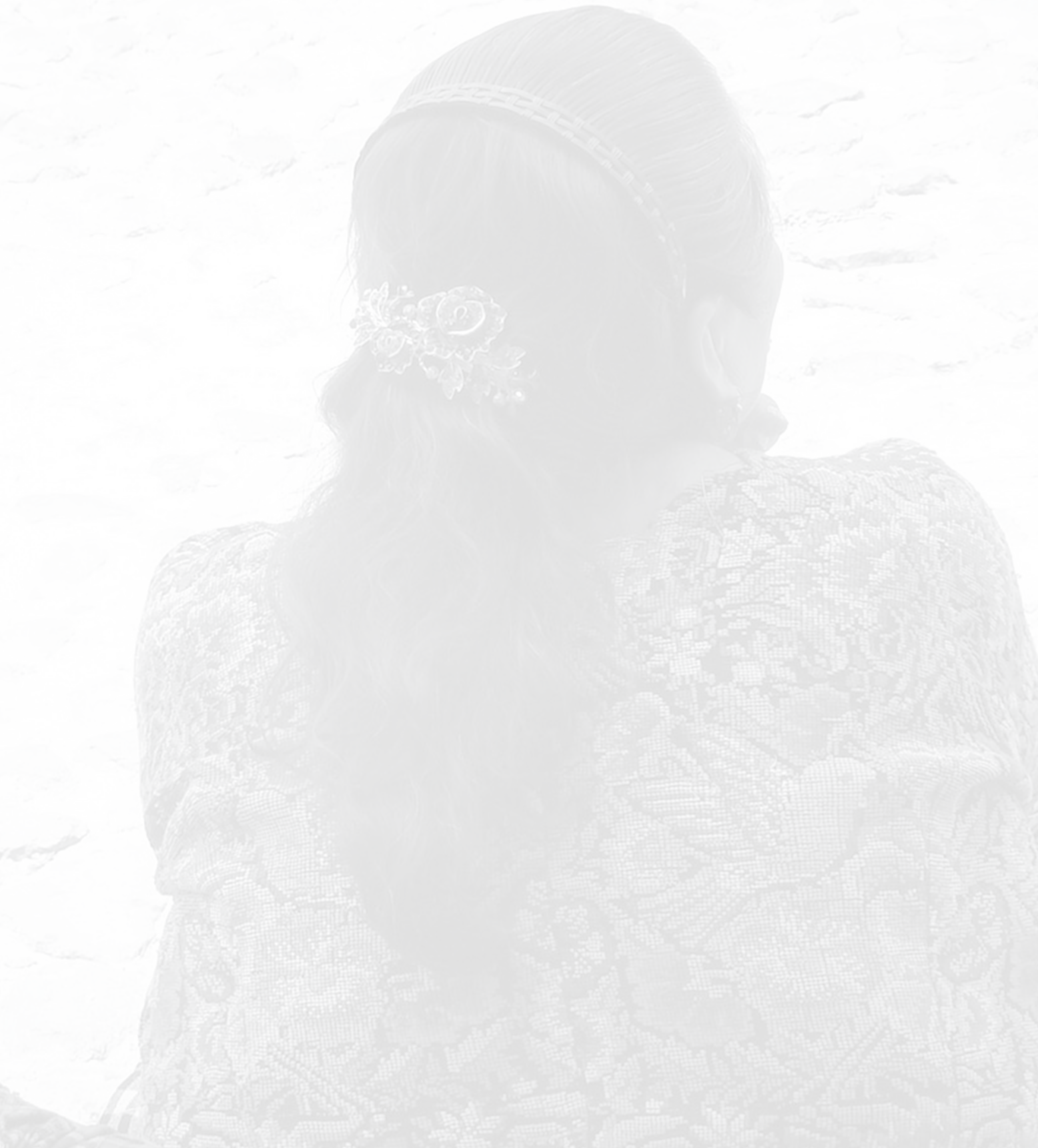




\title{
Participación e incidencia del sujeto político colectivo en la política pública ${ }^{2}$
}

\author{
Participation and influence of \\ the collective political subject in public policies
}

\section{Resumen}

Este artículo presenta una reflexión en torno al sujeto político colectivo y los procesos reivindicativos como acciones de incidencia, con el fin de identificar a este sujeto y comprender sus posibilidades de actuación en el escenario de la política pública como una labor de participación. Aborda la noción de la participación como derecho y establece una diferenciación entre la participación ciudadana, la comunitaria, la social y la participación desde el enfoque crítico. Finalmente, reflexiona sobre la incidencia del sujeto político colectivo en la política pública, desde las acciones que adelantan para tramitar sus demandas.

Palabras clave: participación, sujeto político, sujeto colectivo, acción colectiva, incidencia, política pública.

\begin{abstract}
This paper reflects on the collective political subject and their claim processes as determinant actions, in order to indentify the subject and understand his possibilities of action in political and public scenarios of participation. It deals with the concepts of participation as a right and sets the difference among citizen, communitarian and social participation, from the critical participation approach. Finally, it reflects on the role of collective subjects in public policies and the actions that they promote to process their claims.
\end{abstract}

Keywords: Participation, political subject, collective subject, collective action, incidence, public policy.

\section{Recibido: 22 de mayo de 2015, evaluado: 19 de junio de 2015, aprobado: 13 de julio de 2015}

1 Magíster en Derechos Humanos, especialista en Comunicación-Educación y comunicadora social por la Universidad Pedagógica y Tecnológica de Colombia, Tunja, Colombia. Correo electrónico: zbenavides31@gmail.com

2 Artículo resultado del estudio El sujeto político colectivo en los procesos reivindicativos de derechos humanos e incidencia en la política en Buenos Aires (Cauca), realizado para optar al título de magíster en Derechos Humanos por la Universidad Pedagógica y Tecnológica, Tunja, Colombia. 


\section{Introducción}

Desde hace muchos años, Buenos Aires (Cauca) ha sido un territorio de constantes resistencias entre los distintos habitantes: campesinos, mineros negros, los dueños de las minas, las multinacionales, etc. En los últimos tiempos han persistido grandes diferencias por los múltiples conflictos sociales que confluyen en el territorio: enfrentamiento con las instituciones locales, regionales y nacionales por permitir la entrada de las multinacionales; enfrentamientos entre afrodescendientes e indígenas por la propiedad y tenencia de la tierra; presencia de grupos al margen de la ley; infracciones al Derecho Internacional Humanitario; contaminación ambiental a causa de la explotación minera; violencia política que se ejerce para romper el tejido social y las manifestaciones de resistencia, y amenazas a los líderes de procesos sociales como estrategia para intimidar y desplazar.

A partir de las graves problemáticas de la región, convergen desde las comunidades diferentes sujetos colectivos, cada uno con acciones propias. Estos se visibilizan en diversos procesos organizativos y se movilizan con el propósito de transformar dichas realidades. Rauber (2006) supone en este sentido:

[Se] entiende por actores políticos a todos aquellos actores sociales capaces de organizarse con carácter permanente que definen objetivos de corto, mediano y largo plazo y proyectan sus acciones hacia la transformación de la sociedad, desarrollando procesos continuos de lucha y simultáneamente, con ello, la consciencia política (p. 36).

Así, pueden considerarse como actores o sujetos políticos a las organizaciones sociales barriales, sindicales, campesinas, de mujeres y religiosas, así como a las fuerzas tradicionales dedicadas a lo político. El sujeto social y político asume la organización como un escenario desde donde puede plantear y ejecutar las acciones que van a contribuir al desarrollo de los objetivos trazados.
Desde esta perspectiva, las organizaciones sociales, campesinas, indígenas, afros, de mujeres, etc., se constituyen como sujetos políticos colectivos capaces de incidir, desde sus acciones colectivas, en la transformación del sistema. Es desde abajo y a partir de su quehacer en cuanto organización como se construye el camino para lograr grandes transformaciones. Así, las organizaciones se constituyen en modos de empoderamiento local, territorial y comunitario, cuyos actores, en su mayoría, vienen pensando el vivir bien, y para eso estructuran propuestas tendientes a transformar lo establecido (Rauber, 2006, p. 38).

A partir de esta idea se infiere que las organizaciones sociales se unen desde su acción colectiva para abrir espacios institucionales en los que se discute la política pública, con miras a incidir en ella, promover sus proyectos como organización $\mathrm{y}$ fortalecer procesos comunitarios.

\section{La participación como derecho}

El derecho a la participación se ha planteado desde distintas concepciones. Una de estas tiene que ver con la democracia representativa, que concentra su ejercicio individual en el derecho al voto en comicios electorales, sea para elegir o ser elegido, al igual que para participar en referendos, plebiscitos y consultas que no incluyen necesariamente un debate previo en espacios públicos o colectivos que potencie acciones constructoras de tejido social, con objetivos e identidades comunes. Su relación con las personas que eligen es delegataria. Esto no niega que existan ciudadanos que, desde la visión clásica del liberalismo, participen en organizaciones políticas, sociales y comunitarias en las que el logro de un interés particular se articule y complemente con los intereses colectivos. En el caso colombiano, se da la democracia representativa, porque tiene ocurrencia en procesos políticos eleccionarios; y también se evidencian algunas formas de democracia participativa, pero con todos los vicios de la manipulación de los que ostentan el poder. 
Otra postura tiene ver con la democracia participativa, concebida como una forma de vida, una reflexión continua sobre la construcción de la vida, de la sociedad y de las relaciones que se entretejen entre los distintos actores sociales. Los derechos permiten que los sujetos sean "responsables de una comunidad de personas libres e iguales" (Habermas, 1999, p. 232).

Ahora bien, la democracia participativa, en el ejercicio de la toma de decisiones y el control social sobre su ejecución, no es ninguna concesión del sistema, sino una construcción histórica que surgió con el fin de profundizar la democracia. La democracia participativa radica en la institucionalización de la participación ciudadana en lo relacionado con las políticas públicas; por lo tanto, son muchos los dispositivos en todo el mundo orientados a consolidar una democracia participativa: presupuestos participativos, consulta previa, consejos barriales, desarrollo comunitario, entre otros.

Movimientos y organizaciones sociales han sido protagonistas de este proceso al crear escenarios importantes como el Foro Social Mundial, en el que se debate aquello que afecta a la gran mayoría de la población mundial: los derechos sociales. Así, en contraposición con la dictadura de la única verdad de los mercados: la economía, otro mundo es posible, uno en el que la democracia participativa se define así:

Un modelo de ordenamiento social y político basado en un imaginario cuyos elementos centrales son el pluralismo, la tolerancia, el respeto por la diferencia, el amparo de los derechos y libertades y un alto sentido de responsabilidad colectiva. [...] Pero, sobre todo, implica que los ciudadanos estén dispuestos a participar [...] para el logro de sus objetivos personales y colectivos (Velázquez, 1991, p. 64).
En este marco, el derecho a la participación debe comprenderse y aplicarse desde lo que plantea la Constitución Política de Colombia en su artículo 1:

Colombia es un Estado social de derechos, organizado en forma de República unitaria, descentralizada, con autonomía de sus entidades territoriales, democrática, participativa y pluralista, fundada en el respeto de la dignidad humana. [...] Es derecho social y político que fortalece de contenido al sistema democrático que regula las relaciones del Estado con la Sociedad Civil.

Si bien la Asamblea Nacional Constituyente ${ }^{3}$ propuso en 1991 un nuevo modelo democrático, es posible señalar que, pese a los veintitrés años de promulgada la Constitución Política de Colombia, las transformaciones no han sido las esperadas. Así, no se incluyeron mecanismos de participación democrática que fueran deliberativos tanto en el escenario local como en el nacional y que permitieran un real acercamiento entre las comunidades y los gobiernos respecto a la toma de decisiones. Esto derivó en que la demandada democracia participativa se manejara nuevamente por las élites del país, lo que generó la exclusión de otros sectores de los procesos políticos, por ser parte de las minorías sociales, culturales y económicas constituidas históricamente en Colombia.

En este orden de ideas, el constituyente confirió a la sociedad múltiples mecanismos de participación ciudadana mediante los cuales las personas decidían con un sío un no (como el voto, el referendo, la consulta popular, el plebiscito y la revocatoria del mandato); aunque estos no busquen consenso sino confrontar a los electores con las representaciones políticas.

No obstante, la Constitución Política de Colombia de 1991 permitió otros niveles de

3 La Asamblea Nacional Constituyente fue el resultado de una masiva expresión ciudadana que exigió la redacción de una nueva Constitución colombiana que sustituyera la Carta de 1886. Durante el gobierno de César Gaviria Trujillo, los colombianos votaron por personas representativas que se encargarían de discutirla y reescribirla. 
participación que abrieron nuevas posibilidades de movilización de las comunidades; además, reconoció la pluralidad y multiculturalidad de Colombia e introdujo una serie de mecanismos para la protección de los derechos fundamentales. Así, en su preámbulo hace un reconocimiento manifiesto en este sentido:

El pueblo de Colombia en ejercicio de su poder soberano, [...] y con el fin de fortalecer la unidad de la nación y asegurar a sus integrantes la vida, convivencia, el trabajo, la justicia, la igualdad, el conocimiento, la libertad y la paz, dentro de un marco jurídico, democrático y participativo que garantice un orden político, económico y social justo, y comprometido a impulsar la integración de la comunidad latinoamericana decreta, sanciona y promulga la siguiente [...] [cursivas agregadas] (Constitución Política de Colombia, 1991).

El artículo 2 de la Constitución Política de Colombia establece como uno de los fines del Estado facilitar la participación de todos los habitantes en las decisiones que los afectan, así como en la vida económica, política, administrativa y cultural de la nación. Aún más, el artículo 13 señala que todas las personas nacen libres e iguales ante la ley y que, por lo tanto, recibirán la misma protección y el mismo trato de las autoridades, y gozarán de los mismos derechos, libertades y oportunidades sin ninguna discriminación por razón de sexo, raza, origen nacional o familiar, lengua, religión, opinión política o religiosa.

Igualmente, establece que el Estado promoverá las condiciones para que la igualdad sea real y efectiva, y adoptará medidas en favor de grupos discriminados o marginados. Y en el marco jurídico institucional, la participación es un derecho irrenunciable, para lo cual la Constitución del 91 señala en su artículo 270: "La ley organizará las formas y los sistemas de participación ciudadana que permitan vigilar la gestión pública que se cumpla en los diversos niveles administrativos y sus resultados".

De acuerdo con el marco constitucional, la Corte Constitucional - garante y defensora de la constitución política - advierte que la participación debe originarse en los territorios donde se encuentra la población (departamentos, municipios, corregimientos, veredas); constituye una obligación de los entes territoriales integrar y coordinar dicha participación desde todos los niveles para garantizar este derecho. Asimismo, el artículo 103 de la Constitución dispone formas de participación democráticas para las personas en el ejercicio de su soberanía; así, establece los siguientes mecanismos de participación:

[...] El voto, el plebiscito, el referendo, la consulta popular, el cabildo abierto, la iniciativa legislativa y la revocatoria del mandato. [...] El Estado contribuirá a la organización, promoción y capacitación de las asociaciones profesionales, cívicas, sindicales, comunitarias, juveniles, benéfica o de utilidad común no gubernamentales, sin detrimento de su autonomía, con el objeto de que contribuyan mecanismos democráticos de representación en las diferentes instancias de participación, concertación, control y vigilancia de la gestión pública que se establezcan

Por su parte, el artículo 104 dispone que "el presidente de la República [...] podrá consultar al pueblo decisiones de trascendencia nacional. La decisión del pueblo será obligatoria". En cuanto al artículo 105, se señala allí que "los gobernadores y alcaldes, según el caso, podrán realizar consultas populares para decidir sobre asuntos de competencia del respectivo departamento o municipio". Y de igual importancia es el artículo 106, que establece:

Los habitantes de las entidades territoriales podrán presentar proyectos sobre asuntos que son de competencia de la respectiva corporación pública, la cual está obligada a tramitarlos; decidir sobre las disposiciones de interés de la comunidad a iniciativa de la autoridad o corporación correspondiente o por no menos del $10 \%$ de los ciudadanos inscritos en el respectivo censo electoral; y elegir representantes en las juntas de las empresas que prestan servicios públicos dentro de la entidad territorial respectiva. 
Como se ve, la participación es un derecho fundamental reconocido por la Constitución Política de 1991; su interés reside en que todos los ciudadanos, de manera individual o colectiva, pueden formar parte de los procesos atinentes al diseño de la política pública. De esta manera, se convierte en una estrategia esencial en el ejercicio real de la democracia participativa, que permite el reconocimiento de todas las comunidades en el devenir de sus distintos territorios.

\section{Participación ciudadana}

El ejercicio de la participación ciudadana se realiza desde la reivindicación individual frente al Estado, generalmente desde la exigibilidad de los derechos cívico-políticos. Su expresión reside en el derecho al voto en elecciones, ya sea para elegir o ser elegido, o en la participación en plebiscitos o consultas, donde no hay una construcción colectiva y la relación con los otros generalmente se da desde el interés o reclamo particular que no logra trascender a un escenario más amplio. Al respecto, Caruso (2013) argumenta:

En países en conflicto armado y con grandes desigualdades y dificultades para la garantía de los derechos, como Colombia, la mayor debilidad de la participación ciudadana surge del riesgo que implica la acción personal de exigir derechos, ya que la experiencia demuestra que en determinadas regiones la exigibilidad de derechos aumenta los riesgos de violaciones del derecho a la vida, y requiere de políticas de protección, accionares e incidencias colectivas; un ejemplo son los riesgos de las acciones individuales o de pequeños grupos que casi heroicamente realizan muchas veedurías ciudadanas, y que han llevado a asesinatos y desplazamientos (p. 2).

Generalmente, el control y la presencia ciudadana en las administraciones públicas están asociados a la progresiva incorporación de los sectores excluidos en las instituciones representativas. A diferencia de la participación comunitaria, los que promueven la participación ciudadana propenden a ampliar las vías institucionales, pues ello atrae a diferentes sectores sociales para que - como ocurre muchas veceshagan el puente en el desarrollo de programas y de proyectos que responden a la agenda pública del momento (Torres, 2002b, p. 237) y, de igual manera, para que promuevan los discursos y mecanismos de participación institucionales.

Las organizaciones sociales o el sujeto colectivo no pueden confiar plenamente en este tipo de participación, pero tampoco la deben descartar, pues también representa una oportunidad de aprendizaje y empoderamiento. En el caso de las organizaciones en Buenos Aires (Cauca), este modo de participación les permite realizar acompañamiento sin ponerse en riesgo, si se tienen en cuenta las circunstancias de amenaza por la que atraviesan distintos líderes de la región.

\section{Participación comunitaria}

El concepto de participación comunitaria se refiere a la toma de conciencia colectiva por parte de la comunidad sobre factores que afectan su realidad. Es una forma de construcción de ciudadanía que se construye a partir de acciones colectivas que van configurando identidad.

La participación en lo comunitario surge a partir de la necesidad de organización de las mismas comunidades; en consecuencia, lo comunitario no consiste en una sumatoria de individuos o grupos, sino en un espacio de reconocimiento común. En gran parte, sus experiencias se centran en lo local. Algunos consideran que sus debilidades pasan por la poca sostenibilidad de la movilización comunitaria cuando el objetivo se ha logrado, o bien, por el contrario, cuando no han logrado conquistar su demanda.

Torres (2002a) considera que otros tipos de identidad comunitaria van más allá de lo local y lo inmediato en lo que tiene que ver con asociaciones y movimientos constituidos intencionalmente. En estos espacios colectivos no solo se convoca para advertir y discutir problemas 
comunes, sino por el propósito manifiesto de resolverlos con la acción organizada y en función de unos valores compartidos.

Torres (2002a) también supone que en estas comunidades intencionales, las necesidades son reelaboradas como derechos y reivindicaciones desde donde ponen en juego sus visiones hacia futuro, sus utopías, sus ideologías y sus valores compartidos, con el fin de transformar de manera crítica lo establecido. En esa construcción colectiva, y en la lucha contra otros actores con proyectos diversos, las personas asociadas intencionalmente se convierten en actores colectivos autónomos con capacidad para incidir en las dinámicas sociales.

Si bien estas experticias comunitarias forman parte de grupos sociales excluidos, que se organizan para exigir derechos y transformar sus realidades, también buscan convertirse en fuerzas sociales con capacidad para incidir en las políticas públicas. Del mismo modo, la participación comunitaria es un escenario importante, si se tiene en cuenta que son espacios en los que se dan diálogos directos, compromisos y dinámicas propias; allí hombres y mujeres alcanzan liderazgos importantes para las comunidades.

Adicionalmente, se reconoce lo comunitario para visibilizar el sentido de pertenencia de una colectividad política, base social de la democracia. Como se ha mencionado, en Buenos Aires confluyen distintas organizaciones o se crean espacios asociativos, que aunque no todas son reconocidos en el ámbito regional y nacional, sí inciden en el trabajo que desarrollan. Se deduce así que los sujetos se organizan en estos espacios para aprender, para ampliar su horizonte, pero también para ampliar la participación comunitaria en su territorio.

\section{Participación social}

$\mathrm{Su}$ alcance reside en el fortalecimiento de los sujetos colectivos para la participación e incidencia en la política pública. La participación política implica el compromiso con la transformación de realidades sociales, y en este contexto existe una relación marcada con las comunidades; por ello, sus acciones son completamente contextualizadas.

Los sujetos colectivos (organizaciones y movimientos sociales) deciden qué tipo de país desean y, por consiguiente, qué tipo de participación es coherente con tal construcción. De esta manera, "el riesgoso acercamiento desigual entre la sociedad civil y popular y el Estado los encontrará fortalecidos, con capacidades suficientes para impedir ser absorbidos por un estado autoritario al servicio del mercado, cooptando y suplantando sus voluntades" (Caruso, 2013, p. 67).

Este escenario de la participación social busca plantear la garantía de derechos desde una perspectiva de corto, largo y mediano plazo, a través de la práctica de la democracia representativa, en la que se reconocen las minorías y las diferencias y se construyen procesos en deliberación. En los procesos sociales de organización colectiva se consolidan nuevas y distintas formas de gestión social de lo público, en tanto las prácticas políticas se transforman en prácticas de construcción conjunta, y allí el debate de las ideas es respetado y resulta incluyente. En último término, son experiencias de una real democracia participativa directa.

Es cierto que Colombia ha sido un país cuya configuración histórica ha estado envuelta por diversos fenómenos de violencia estructural (narcotráfico, corrupción, paramilitarismo, conflicto armado, fragilidad de las estructuras democráticas e institucionales que edifican instituciones delictivas y corruptas, por cuanto concentran el poder) y donde se han consolidado realidades complejas de intereses económicos y desconfianzas políticas; por ello se vuelve casi subversivo abordar procesos de empoderamiento con las comunidades, pues esto iría en contravía de la ética utilitarista del mercado y sería sospechoso para los organismos de inteligencia y demás actores de la guerra. 
Frente a un Estado que ha sido incapaz de resolver dichos fenómenos y que, por el contrario, forma parte y es protagonista responsable de ellos, se requieren sujetos políticos que participen activamente en la transformación de dichos fenómenos. Así, sujeto, proyecto y poder se constituyen articuladamente. El sujeto colectivo, en el ejercicio de la articulación y en la función de puente, genera formas de organización que son necesarias para poder cumplir con los objetivos (Rauber, 2003, p. 81); es decir, el sujeto colectivo es un instrumento para lograr fines, no son el fin.

En el escenario del empoderamiento de la participación, los ciudadanos se hacen sujetos activos de sus propias comunidades, y frente a un Estado que no garantiza sus derechos humanos, proceden a exigirlos, pues como se ha visto, a los ciudadanos se les ha reservado la participación como sujetos pasivos, esto es, se limitan a convalidar decisiones tomadas por el establecimiento, pero sin haber participado en su discusión y consenso. Por el contario, la propuesta es la creación colectiva; como plantea Rauber (2003), no es la representación tradicional política sino los sujetos colectivos los que deben asumir la capacidad de pensar, crear, decidir, asumir responsabilidades, hacerse cargo de los resultados de sus decisiones, asumir las equivocaciones de dicha creación colectiva.

Se trata, entonces, de configurar nuevas y distintas formas de participación activa respecto a las decisiones, contexto en el que los sujetos colectivos puedan ser protagonistas en el pensar y el hacer de su propia historia. De esta manera se construyen escenarios contextualizados a partir de las reales necesidades de las comunidades.

\section{La participación en perspectiva crítica}

Según lo expuesto hasta ahora, se infiere que la participación no debería ser entendida como una acción formal en la que las personas conva- lidan decisiones ya tomadas por las instituciones; por el contrario, "la participación estaría dada por la posibilidad de los individuos y colectivos sociales de incidir en la toma de decisiones frente a asuntos públicos o particulares que los afectan" (Torres, 2002b, p. 234).

Desde una perspectiva crítica, la participación no significa tomar parte de, sino que es una conquista, una lucha por derechos que han sido negados históricamente; por ello, la participación no puede asumirse como algo dado, sino que es un proceso: "La participación se construye, se desarrolla, a través de un número de pequeñas acciones, no pudiendo ser adquirida de repente, por un acto jurídico, o un decreto" (Posada, 1997, p. 19.)

La participación también implica una relación dialógica, es decir, entre iguales en derechos, así como entre los sujetos y sus organizaciones sociales. Se busca, en suma, que a partir del intercambio de saberes, del debate y del análisis crítico de sus realidades sociales y políticas, los actores desarrollen capacidades para elaborar sus propias propuestas, para abordar sus problemas tanto internos como los concernientes al Estado y a sus políticas públicas.

Ahora bien, la participación está orientada a generar procesos de articulación e interlocución con las formas organizadas de la sociedad, para establecer el diseño y la implementación de la política pública y lograr la integración de las necesidades más sentidas y las expectativas de toda la población. Así será posible generar propuestas que puedan articularse de manera efectiva y real, por medio de procesos organizados que deriven en acciones participativas de las comunidades involucradas que pretenden la atención del establecimiento público, en la mejora de sus condiciones de vida (Caruso, 2013, p. 14).

Los anteriores escenarios pertenecen a la esfera pública, donde las organizaciones han construido progresivamente su condición de sujetos políticos colectivos capaces de movilizarse para transformar la realidad. 


\section{Incidencia en política pública}

La incidencia en política pública debe ser una labor de planeación participativa realizada desde espacios de lo público y que comprometa a las instituciones responsables de la garantía de los derechos humanos. Al respecto, Tapia et al. (2010) plantean:

El término incidencia se entiende también como influencia. [...] Como organizaciones podemos transformar las condiciones de vida de los beneficiarios con quienes trabajamos, influir en las decisiones de otras organizaciones o incluso en las decisiones de nuestros donantes. Sin embargo, el tema de incidencia en políticas públicas hace referencia explícita a las acciones que llevamos a cabo y que tienen consecuencias directas para las políticas que decide e implementa el gobierno (p. 12).

Si bien gran parte de las organizaciones sociales en Buenos Aires no tienen la facultad de tomar decisiones en la política pública, sí logran incidir en ellas, puesto que mantienen una relación constante con instituciones del Estado, ya sea desde el trámite de sus demandas y reivindicación de derechos o desde la labor de mediadores en la ejecución de sus políticas a través de proyectos. Inciden también a partir de las diversas acciones que adelantan con las comunidades, así como mediante la labor de resistencia y movilización frente a situaciones de violación de derechos, pues logran persuadir a instituciones del orden local departamental $-\mathrm{y}$ algunas veces nacional- respecto a la orientación y efectividad de políticas públicas para su territorio.

Sus estrategias son diversas: procesos formativos en derechos humanos que han permitido un empoderamiento para exigirlos; diálogos y concertaciones con el gobierno en temas del sector agrario y minero; suministro de información para el diseño de diagnósticos locales, a través del seguimiento que hacen a la política pública en los ámbitos local, regional y nacional; las convergencias de distintas organizaciones sociales e institucionales con el fin de promover acciones que contribuyan a la paz, etc.

Para que los sujetos colectivos puedan llevar a cabo sus misiones y logren incidencias relevantes en las comunidades, deben participar en el diseño y la ejecución de la política pública. Su participación resulta relevante, toda vez que ellos, por su trabajo y su vivencia en las comunidades, pueden hacer grandes aportes a la planeación, pues esta se realizaría de manera contextualizada, es decir, teniendo en cuenta el contexto territorial, político, social, cultural y étnico. Esto va a permitir que las estrategias puedan ser más efectivas.

Según esta idea, debe entenderse que las políticas públicas son una construcción colectiva y participativa en la que confluyen las instituciones y los sujetos colectivos, con el propósito de planear en perspectiva de derechos y mejorar la calidad de vida de las personas. Por lo expuesto, se infiere que la planeación no debería ser entendida - como ocurre en la mayoría de veces- como un asunto burocrático y formal, sino, sobre todo, como una práctica social y política, resultante de la dinámica que imprimen a la sociedad los intereses en conflicto; por tanto, esta planeación supone compromisos que puedan concretarse en la medida en que haya conciencia de los intereses y voluntad de defenderlos (Posada, 1997, p. 19).

Ahora bien, es una práctica social por cuanto es una tradición o una costumbre de las comunidades; y es una práctica politica porque representa opciones, decisiones y prioridades. Allí los intereses y conflictos se expresan por cuanto hay un actor estatal que busca validar sus proyectos y programas de acuerdo con sus metas, que entran en tensión con otros fines no coincidentes. En consecuencia, se hace necesaria la conciencia de los intereses, es decir, que las personas problematicen de manera crítica las demandas, las necesidades y los derechos que se están vulnerados en el contexto donde se está llevando la política. Esta condición de los intereses se constituye en un rasgo fundamental de la participación, que parte de una problematización 
en perspectiva de derechos humanos en relación con las demandas necesidades y los saberes de los sujetos políticos.

Finalmente, la participación de los sujetos colectivos en el diseño y la planeación de la política pública - escenario de reivindicación de derechos colectivos - contribuye a ampliar la democracia, toda vez que permite la convergencia de distintas miradas. En este sentido, es necesario entender al sujeto político colectivo desde una perspectiva que dé cuenta del proceso en el que las acciones dirigidas por este tienen un carácter colectivo y reivindicativo.

Conviene subrayar que son diversos los escenarios en los que el sujeto político se ve invocado a participar a través de los distintos mecanismos que se han dispuesto desde la norma. Estos mecanismos, si bien son importantes, devienen en espacios que niegan un proceso dialógico entre la ciudadanía y el sujeto político colectivo con las autoridades municipales.

Otro escenario de participación del sujeto es aquel en el que puede incidir directamente en las políticas públicas, ya sea desde la participación ciudadana, la participación comunitaria o la participación social. Se rescata la perspectiva crítica de la participación, que implica una relación entre iguales en derechos; aquí el sujeto político colectivo es un actor fundamental en el ejercicio del diseño y la ejecución de la política pública. Desde esta perspectiva, el sujeto político colectivo se organiza en torno a problemáticas o violaciones de derechos humanos que afectan a sus comunidades, con el fin de contribuir a transformar esa realidad por vía de la acción participativa. En este marco de la participación, el sujeto político colectivo, si bien no incide directamente para tomar decisiones en la política pública, sí incide desde las distintas acciones colectivas como estrategia.

Por consiguiente, se trata de configurar y fortalecer nuevas y distintas formas de participación activa en las decisiones, y allí los sujetos colectivos son protagonistas en el pensar y el hacer de su propia historia. De esta manera se realizaría una democracia participativa que se construye desde escenarios contextualizados, desde las reales necesidades de las comunidades.

\section{Referencias}

Caruso, M. A. (2013). Democraciaparticipativa directa: de la Comuna de París a los gobiernos de izquierda en América Latina. Bogotá: Jack editores.

Congreso de la República de Colombia (1991). Constitución Politica de Colombia.

Guzmán, A. (2012). Democracia participativa en Colombia: un sueño veinte años después. Jurídicas, 8(2), 30-41.

Habermas, J. (1999). ¿Qué significa política deliberativa? En La inclusión del otro. Estudios de teoría politica (pp. 231-247). Barcelona: Paidós
Posada, J. (1997). Participación comunitaria e interculturalidad en la escuela pública. Pedagogia y Saberes, 10.

Rauber, I. (2003). América Latina. Movimientos sociales, representación politica. Bogotá: Desde Abajo.

Rauber, I. (2006). Sujetos politicos. Rumbos estratégicos y tareas actuales de los movimientos sociales y politicos en América Latina. Santo Domingo, República Dominicana: Centro de Investigación y Promoción Social (CIPROS). 
Tapias, M. et al. (2010). Alternativas y capacidades. Manual de incidencia en politicas públicas. México. Alternativas y Capacidades. Recuperado de http://www.alternativasycapacidades.org/sites/default/files/MIPP.pdf

Torres, A. (2002a). Historia y sujetos de la educación. Pedagogía y Saberes, 12.

Torres, A. (2002b). Movimientos sociales, organizaciones populares y constitución de su- jetos colectivos. Reconstruyendo el vínculo social. Bogotá: Universidad Nacional Abierta y a Distancia.

Torres, A. (2007). Identidad y politica de la acción colectiva. Organizaciones populares y luchas urbanas en Bogotá. Bogotá: Universidad Pedagógica Nacional.

Velásquez, F. (1991). Una democracia participativa para Colombia. Revista Foro, 16, 64-69. 